\title{
LIBERTARIAN PHILOSOPHY VERSUS PROPERTARIAN DOGMA: A FURTHER REPLY TO BLOCK
}

\author{
J. C. Lester \\ Independent scholar, London, UK
}

CMESTE

JEL Category: P10

\begin{abstract}
This replies to Block 2019 (B19), which responds to Lester 2014 (L14). The main issues in the, varyingly sized, sections are as follows. 1 Further explanations of critical rationalism, the theory of liberty, and problems with the non-aggression principle. 2.1 The relationships among law, morality, and libertarianism. 2.2 The objective invasiveness of low-level radiation and that it is therefore a proactive imposition (albeit trivial) if someone inflicts it on non-consenting people. 2.3 The objective and subjective aspects of proactive impositions; and how clashes can be resolved. 2.4 How liberty relates to risk and self-ownership. 2.5 Libertarian initial acquisition versus absolute property rights by labour-mixing. 2.6 Organisational note. 2.7 Libertarianism and mens rea. 2.8 Libertarian rectification versus lex-talionis doubling. 2.9 Indirectly clashing rights, self-preservation, trespasser-hiker, flagpole-grasper, and landmine-layer. 2.10 A logical point is not a moral point. 2.11 Pacifism and libertarianism. 3.1 A weak criticism of utilitarianism. 3.2 Hedonometers; approximate interpersonal comparisons of utility imply libertarianism; what a libertarian is; libertarian rankings. 4. Libertarian philosophy versus propertarian dogma. Coda: the need to take seriously the philosophical problems with propertarian-justificationist libertarianism. Readers that might be interested include those engaging in libertarian philosophy and those using the Rothbardian/Blockian theoretical approach to libertarianism.
\end{abstract}

Keywords: libertarianism; philosophy; private property; rights; crime; law; critical rationalism

\section{OVERVIEW}

This essay is a reply to Block, 2019 (hereafter B19). ${ }^{1}$ B19 will be quoted, usually using indented

The address of the author:

J. C. Lester

䒠jclester@gmail.com

${ }^{1} \mathrm{~B} 19$ is a response to Lester, 2014 (hereafter L14). L14 is itself a response to Block, 2011 (hereafter B11). text, and then replied to at significant relevant points. Repetition of issues will be avoided unless some new aspect arises, or a clarification appears desirable. Many relatively trivial points of disagreement will be ignored. This essay is written in impersonal text. ${ }^{2}$ For ease of reference, B19's headings are followed but put in inverted commas.

2 As far as is practical, all references are to objective texts and arguments rather than to any persons. This helps to avoid invalid ad hominem arguments and irrelevant personal matters. 
It will be argued that most of B19's errors are the result of attempts to reply to L14's philosophical arguments by merely restating the same positions or misinterpreting what $L 14$ says.

\section{"1 INTRODUCTION"}

B19 fails to grasp critical-rationalist epistemology. It does not explicitly even mention it, or fallibilism either. That epistemology was briefly explained in L14. It is not possible to give an elaborate explanation and defence of that epistemology here, but a further short attempt might be helpful. ${ }^{3}$ All observations, arguments, explanations, and even logical inferences rest on, and thus logically amount to, assumptions (i.e., conjectures). They thereby cannot offer support that transcends or justifies $^{4}$ their assumptions (but those assumptions are either true or false dependant on the relevant facts, i.e., the way things really are). Any attempt to provide support will face the logical trilemma of entailing circularities, infinite regresses, or dogmatic assumptions. However, assumptions can be criticised or tested-all within a framework of assumptions, of course (and presumably reality will tend to aid true assumptions to withstand criticisms and tests better than false ones, and true ones should resurface even if mistakenly rejected). ${ }^{5}$ None of this entails that we cannot possess or know (in an unsupported sense) what are true (i.e., accurate) beliefs or theories; or how is it that people appear to survive and even thrive? Therefore, if critical rationalism is scepticism, then that is only in the sense that it holds there to be no epistemological certainty or support. It is not scepticism in the sense that psychological doubt ought always to be felt (which does not appear to be psychologically possible) or that it is impossible to have knowledge in the sense of the possession or awareness of true theories (and even false theories are in one sense 'known', if one is aware of them as theories).

B19 responds to a relevantly similar explanation in L14 thus:

this is such ultra-skepticism; it is difficult to base any coherent examination of the Friedman-Block controversy on it or anything else for that matter. (128)

Nowhere in L14 is "ultra-skepticism" (or even 'scepticism') mentioned. Critical rationalism is not "ultra-skepticism". As explained, we know by possessing a true assumption; not by having certainty or justificatory support for that assumption. We "base" any "examination" on assumptions (but they might be false). That is both "coherent" and necessarily true.

unless Lester can come up with specifics, and he does, undermining his own extreme cynicism, he cannot help resolve any such difficulties. (128)

Critical rationalism is not "extreme cynicism" either. It is a modest acknowledgement that epistemological support is logically impossible combined with the practical corollary of an antidogmatic approach to criticism and to competing theories. There are no genuine "difficulties" with this that are cited in B19.

if we are compelled to reject all that seems definitively true (128)

This is a hopeless misinterpretation of critical rationalism. We are only logically "compelled" to admit that all we have are fallible, unsupported, assumptions (although some of them may be wellexplained and well-tested; and thus, critically preferred).

and Lester maintains that it is definitively true that we must doubt everything (128)

ostensible counterexamples by adequately responding to them (which cannot, of course, offer any support to the conjecture: it merely appears to remain intelligible and unrefuted so far).

${ }^{5}$ For detailed explanations of critical rationalism see, for instance, Popper, [1963] 1978 and Miller, 1994. 
It is not a matter of "definition" but logic that we cannot get beyond assumptions to achieve epistemological support. It is an illogical delusion that we can. But that does not imply that, psychologically, "we must doubt everything".

Lester's claim that radical skepticism is the third basis of libertarianism seems patently false. (128)

The abstract theory of liberty is central; critical rationalism is only the epistemology. And this eleutherological-conjecturalist libertarianism is only "third" compared to B11's two: deontologism versus utilitarianism (or, probably more accurately, consequentialism); B11 omits contractarianism and other possible 'bases' (i.e., explanations). The desirability of the ideology of libertarianism has to be a conjecture that can be explained and defended but not supported, as we necessarily have assumptions all the way down. Epistemologically, there is no "basis of libertarianism". There are, of course, different conjectural approaches that are used to explain and defend it.

It would appear that he makes this up as he goes along, with no justification for it whatsoever. He offers no evidence for his claim. (128)

An explanation of critical-rationalist libertarianism is offered in L14, and B19 offers no sound criticism of it. Lapsing back into complaining that there is "no justification" or "evidence for" that explanation is to fail to address its arguments that there cannot be such things.

... no refutation is ever justified either." But if this is true, it is difficult to see how he can refute my refutation of Friedman (128)

By offering conjectural refutations that themselves withstand criticism (and so they may be provisionally conjectured to be sound).

after relieving himself of these skeptical thoughts, he leaves off them and never discusses them again. (129)

L14 contains objective fallibilistic arguments rather than any "skeptical thoughts". Critical rationalism is explicitly cited in the later sections $3.5,4$, and dealt with at length in the appendix (although that is not a reply to B11). Moreover, it is the epistemology that is assumed and evident throughout L14. Without understanding this, the rest of the text is liable to justificationist misinterpretations of just the kinds that B19 does fall into (as will be seen).

B19 then quotes L14 as it outlines a theory of libertarian liberty, and comments that "even at this early stage of the development of his views, he is not fully correct" (129). In other words, B19 is not criticising L14 as though it is offering a philosophical theory of liberty but, rather, as though it were a misunderstanding of the overall theory of libertarianism assumed in B19. In fact, B19 itself offers no theory of liberty whatsoever and does not appear to recognise that this absence is a problem for its so-called "libertarianism".

B19 asserts that with,

libertarianism ... it is fully compatible with this view of what the law should be that some people are "constrained by other people's interferences." (129)

1) L14 is not, at that point, outlining an overall theory of "libertarianism" but an abstract theory of the relevant kind of liberty. 2) It is explicitly stated that this is a "pre-propertarian" theory; but B19's quotation cuts off just before that crucial part of the text. 3) Any discussion of "law" is irrelevant to the abstract theory at this stage. Therefore, the succeeding discussion assuming "I buy a loaf of bread", etc., is also irrelevant. B19 then makes the same mistakes when criticising "proactively imposed costs".

Nevertheless, the things that B19 says here are approximately correct as regards the best ways to promote maximum liberty in practice. But this can only be philosophically understood after, 1) explaining the abstract theory of interpersonal liberty, 2) deriving what the libertarian policies should be in principle if full liberty is not possible or not observed, 3) deriving what is objectively entailed as regards instantiating that liberty in normal practice, and 4) explaining the libertarian usefulness of institutionalising these things as property where appropriate (normative defences 
of such libertarianism is a fifth stage). ${ }^{6}$ Therefore, B19 is trying to run before it has learnt to walk as regards these philosophical matters. ${ }^{7}$ It is, of course, possible to explain and defend a crude 'libertarianism' on purely propertarian assumptions that ignore all the philosophical issues. But it is not possible to refute philosophical arguments on the subject with dogmatic propertarian assumptions.

B19 quotes L14's "three possible problems" with B11's "nonaggression principle" (NAP): 8

1) This statement is fine as long as he means "based" only in an explanatory sense, but not if he means it in any kind of grounding or justifying sense. 2) He cannot be literally right to explain this as "no one may properly initiate violence against another person or his justly owned property." For a thief need not use violence (e.g., when shoplifting: a shoplifter is not thereby a 'violent criminal', is he?). And libertarian police may legitimately initiate violence against a non-violent thief, if necessary. 3) Any actual theory of liberty is at best tacit. (129)

B19 quotes B11 at greater length than did L14, then says, "I do not think it is incumbent upon me to take back a single word of this statement" and proceeds to elaborate. How does the elaboration answer any of L14's "three possible problems"?

1) L14's first point is a reference to the arguments of critical rationalism about the impossibility of "grounding or justifying" (of which B19 had erroneously said L14 "never discusses them again"). B19 appears to misinterpret this as a request for "either 'explaining' or 'justifying"' the NAP. B19 then asks, "Does Lester believe that the NAP has nothing to do with libertarianism?" Answer: it is one approximate and confused shorthand way of stating what libertarianism usually requires, but only after libertarian property has-after several stages-been derived from applying an abstract libertarian theory of liberty.

2) B19 actually admits that "shoplifters, and pickpocket[s ...] and those who engage in bad check writing and other types of fraud are not 'violent'." Right, then the account that "no one may properly initiate violence against another person" cannot literally be a correct explanation of the NAP. Yet B19 still insists that L14,

is mistaken in thinking that "libertarian police may legitimately initiate violence against a non-violent thief." When and if they properly use violence, they would not thereby be initiating it; rather, they would be reacting to a prior denigration of the NAP on the part of the criminal. (129-130)

But B19 has just admitted that such criminals are "not 'violent"'. Therefore, the police, ipso facto, must use violence first. However, B19 could make sense if "violence" were only changed to "property violation" (or "legitimate-property violation", where "legitimate" requires further explanation as to how it relates to a theory of liberty). Writing coherently in English, instead of careless contradictory nonsense, is all that is required.

3) B19 says nothing whatsoever about "any actual theory of liberty".

On all three points, then, B19 has failed to respond even slightly adequately. Instead, B19 has repeated some of the dogmata of NAP 'libertarianism'. This is just the sort of response that is typical of an approach that assumes that a position is 'justified' and so any criticisms of it can be dismissed as based on a misunderstanding that only can be remedied by further study of the 'full justification'. Hence, again, the relevance of critical rationalism to dispel this dogmatic delusion.

But now there is a better introduction that is Lester, 2019 (but it might be best to first read Lester, 2020a and 2020b).

8 It is not accurate for B19 to interpret these criticisms as a personal reproach: "Lester upbraids me".
${ }^{6}$ For a one-page explanation of "How Abstract Liberty Relates to Private Property" see Lester, 2020a. For a one-page guide to "EleutherologicalConjecturalist Libertarianism" see Lester, 2020b.

${ }^{7}$ Some of the more elementary errors might have been avoided if B19 were to have been informed by chapter ten of the same book that includes L14. 


\section{“2 INITIAL CRITICISMS"}

\section{"2.1 Initiation of coercion"}

B11's analysis of the Nazi-guard example is solely supposed to "establish a distinction, no, a chasm, between law and morality" (B11, 4). L14 briefly explains that the example is unnecessarily problematic as regards what it is supposed to "establish" and so a simpler example is preferable. B19 is at pains to defend B11's analysis. But L14's point is not that the analysis is demonstrably flawed; it is that it introduces too many gratuitously complicated and irrelevant elements to make for a clear argument to defend B11's thesis. That is bad philosophical method. Therefore, it is pointless to attempt to go into the example in any detail. Finally, B19 asserts that L14 "casts doubt on the veracity of the actual Nuremberg findings". This is a completely inaccurate and even libellous interpretation. L14 merely points out that "without going into details, the Nuremberg Court is problematic as an example of libertarian law in action". The "veracity" of the "findings" is not mentioned. It clearly wasn't a libertarian court: set up and run on libertarian principles to apply libertarian law. Again and again B19 resorts to hyperbolic, inaccurate, logically invalid, rhetoric when what is required is careful, precise, philosophical analysis.

B19 then quotes at length L14's car-stealing example and explanation that,

libertarianism is an ideology. Therefore, it contains both factual and moral theses. Broadly understood, these theses are that liberty generally promotes human welfare and is moral. In fact, the law does not need to be mentioned at all. (131)

And L14 goes on to explain how libertarianism "it is not inherently about law at all and it is inherently about morals (qua ideology)".

Bizarrely, B19 says "libertarianism solely concerns 'what the law ought to be.' Lester and I agree on that" (131). No. L14 explicitly states and argues otherwise and is actually quoted doing so by B19 (indented above). And B19 fails to fault what L14 says. Libertarianism is, first and foremost, an ideology about the desirability and morality of interpersonal liberty (the clue is in the name). In practice, this will usually involve having property rights that fit such liberty. But in theory, it could involve people interacting on a consensual basis without the institution of the law even existing. However, B19 has no explicit theory of interpersonal liberty; it has only a theory of absolute property that is labelled "libertarianism" for no apparent reason.

B19 does not offer precise criticisms of the arguments in L14. Instead, it attempts to elaborate its own theory of so-called "libertarianism". B19 says,

Stipulate that it is immoral to get drunk, to engage in prostitution, to commit suicide. ... They are all compatible with this ideology. Thus, "libertarianism is["] not at all ["]partly a moral theory." (131)

The main problem here is "thus". Stipulate that "libertarianism [or, for instance, veganism] is partly a moral theory" (as most libertarians, or vegans, surely believe). It does not follow that it is the whole of morality. Therefore, finding that something is "immoral" but compatible with libertarianism (or veganism) is not a refutation. And it is not inconsistent to hold both that activity $X$ is immoral and that it would be even more immoral to forcibly prevent $\mathrm{X}$.

\section{B19 continues,}

Another error, here, is to say that libertarianism contains a "factual" thesis. Yes, "liberty generally promotes human welfare" but this is a positive statement, not a normative one, and libertarianism lies entirely within the latter realm. (131)

1) Libertarianism, as an ideology, usually involves indefinitely many "factual theses" (i.e., positive and not normative theories) about how the human world operates. Thus, the first sentence, as it literally stands, is itself an "error". 2) B19 is actually agreeing with L14 when it states that it "is a positive statement, not a normative one" that "liberty generally promotes human welfare". 3) The final proposition uses "latter", which on a natural reading refers to "normative" when it presumably intends "positive". 4) How can even B19's "libertarianism" be entirely "positive" when B19 states that "libertarianism solely concerns 'what the law ought to be"' (131)? How can that "ought" not be moral? As ever, B19 offers careless reading, careless writing, and careless logic. As a 
philosophical argument, the whole essay reads like a paradigm of the Dunning-Kruger effect.

B19 then alleges a "blatant" contradiction among three statements in L14: that libertarianism is (to focus on the relevant words) 1) "at most, a theory of what the law ought to be", 2) "not inherently about law at all and it is inherently about morals", and 3) "not a theory of law, as such, and there might not even need to be laws in a libertarian society" (B19 misleadingly quotes this, here unexplained, conclusion taken from the next section). Viewing these statements as contradictory is more careless reading and reasoning in B19.9 The same points can be expressed in slightly different form, just in case that helps. 1) Libertarianism (or, by analogy, utilitarianism) can be applied to what the law ought to be. 2) That means that libertarianism (or utilitarianism) is not inherently a theory of law (or it could not exist prior to the law in order to be applied to it). However, advocating interpersonal liberty is, at least typically (but see 3.2), inherently moral. 3) Therefore, libertarianism (or utilitarianism) is not in itself a theory of law and, in theory (i.e., conceivably), a society could have maximal liberty (or utility) without having law. Any careful reading ought to show that there are no "blatant", or even implicit, contradictions here. The confusion might be being partly caused by the fact that B19 has no explicit theory of liberty (and refuses to acknowledge that fact or discuss why that is). Therefore, it can only jump straight into some version of 'libertarianism'-in-practice and misperceive this as 'what libertarianism really is'. Utilitarian texts typically explain what utility is before it is then applied. Why can't "libertarian" texts explain what liberty is before it is then applied? Because they are philosophically shallow $^{10}$ (even Philistine) and really privatepropertarian first and foremost.

Concerning the second part of the third point, B19 asserts that

9 It is philosophically on a par with reading a theoretical libertarian defence of contractual slavery and then interpreting that as a defence of actual historical slavery as it was practised in the U.S.
Lester falls into the Marxist trap of thinking that under a libertarian society, [t]here would be such a thing as "libertarian man" akin to the "communist man" of the Marxists. No, even in an otherwise libertarian society, it is extremely likely that there will still be a few murderers, rapists, thieves and other reprobates. Libertarians, apart from Lester, are typically more realistic on such matters. (131, footnote 12)

Here B19 has omitted the more explanatory part from the section that is supposed to be under discussion: "if a society were to comprise only libertarian people, then - in principle - there might not need to be any law". It ought to be clear that this is a thought-experiment about what is conceivable and not any kind of assertion about what is realistic. It assumes away, for the sake of argument, just what B19 is invalidly reintroducing: "that there will still be a few murderers, rapists, thieves and other reprobates". (That said, who knows how civilised a libertarian society of abundance might eventually become in the indefinitely far future?)

\section{"2.2 Absolute control"}

Friedman severely upbraided Rothbard (1982A) over radio waves, and Lester followed suit. What did Rothbard do to deserve such calumny? (131)

At no point is any person "severely upbraided" in L14. There are only philosophical criticisms and arguments. More absurd still is B19's accusation (calumny?) of "calumny": "a misrepresentation intended to harm another's reputation" (The Merriam-Webster Dictionary).

B19 then quotes Rothbard on this issue and L14's criticism. B19 says that,

low-level radiation ... is "all around us." That is to say, it most certainly is not "objectively

10 This includes Nozick, 1974; which is undoubtedly philosophically sophisticated but ultimately at a shallow level. 
invasive of other people's property," or their persons. (132)

This is clearly confused. Natural low-level radiation penetrates (or is "objectively invasive", in a non-normative sense) people and their property. But when person $A$ uses a device such as a mobile phone that generates a source of low-level radiation that does this to person $B$ or his property, then $A$ has proactively imposed this radiation on B. However, as B19's quoted articles explain, it is trivial and not known to affect health adversely. Moreover, it is often reciprocal: many people use mobile phones and highly value their usage. Hence maximising liberty seems to entail toleration of such devices.

\section{B19 continues,}

It is not that there is "undetected damage (that is) is acceptable." It is rather that this socalled "damage" is undetectable, apart from the use of special technology. Why call it "damage" then, when the victim simply cannot be even aware of it, not with his five senses in any case, nor does it harm him, from an objective medical point of view. Thus, there are simply no "sense interferences (that) need to be tolerated if liberty is to be maximized." Liberty does quite well with "incursions" of this sort. (133)

L14 points out three fairly obvious theoretical problems with B11's quoted criterion that "What counts is whether the senses of the property owner are interfered with". L14 does not assert that radio waves cause "damage". Therefore, this is a strawman attack by B19. Incidentally, this is the first time that B19 itself uses the word "liberty" (rather than quoting L14's use of that word). Unfortunately, we are still not told what L19 understands by "liberty".

B19 adds,

Lester in this section also mentions "clashes of liberty." He is very much mistaken in this point as well. Under libertarianism, it is akin to a logical contradiction for there to be a clash of rights. If there appears to be one, then one or the other of these supposed rights, or, both of them, are mis-specified. If there were any such thing, then the freedom philosophy would have no answer to a given problem, a lacuna very much to be avoided.

This paragraph epitomises the problems with B19. Some points can be enumerated. 1) This simply ignores the very different theories of liberty and libertarianism explained and applied in L14. 2) Instead, it merely briefly outlines the problematic theory that L19 advocates. 3) "Under libertarianism" implies that the interpretation of libertarianism that B19 wishes to defend is the correct and sole version. 4) Suddenly this paragraph switches from the topic of liberty to the different topic of "rights". 5) Are these supposed to be rights to liberty? If so, there must first be something that liberty is, both in practice and in abstract theory. We are not told what in either case. 6) It is a separate question when and how there are rights to such things.

\section{"2.3 Super flashlights"}

B19 asserts,

the everyday flashlight cannot violate property rights by being shined on a house. (134)

When a torch (flashlight) is shone on a house, then it is objectively the case that photons are being proactively imposed on the property of the house owner. In the normal case, of course, this is not anything that the owner cares about; and so it can and will be ignored.

He offers no solution to this "problem" apart from his very subjective weighting of greater and lesser impositions. (134)

In the assumed example, one person's property is being objectively imposed on ('photon trespass') by another person's activities. Assume that the eccentric and curmudgeonly house owner objects to the light's being shone on his house. Then by absolute property rights it looks as though he can veto it. However, this only looks at half the problem. If his neighbour cannot use his torch normally, or even switch on his house lights without blackout blinds, then he would typically thereby be being proactively imposed on to an even greater degree. This is not "very subjective": 'reasonable man' standards could usually be used to solve the problems of any such clashes of liberty. However, there is an inherently ineradicable subjective aspect to all liberty-as 
B19 might have discovered if it had attempted to formulate an abstract theory of interpersonal liberty (or been informed by more of the essays in the same book as L14).

B19 offers what is supposed to be a "reductio":

I value punching Lester in the nose at the level of $\$ 100$. He disvalues this at only $\$ 80$. So, according to his analysis, if I punch him in the nose, GDP rises by $\$ 20$. But more; and worse. Would it be a violation of libertarianism for me to punch him in the nose from his perspective? No. Because GDP will in this way be raised. (134)

It appears, ex hypothesi, that a trade might be possible. However, in the absence of a trade the punch proactively imposes on another person and thus flouts liberty. GDP has nothing to do with it. This is the sort of irrelevant confusion that occurs because B19 is informed solely by economic and propertarian theory rather than by any grasp of the philosophical arguments.

After a confused digression, B19 then jumps to quote the end of the next section:

Opines Lester: 'Rothbard is said to be right where he says, "Only if the radio transmissions are proven to be harmful to Smith's person beyond a reasonable doubt should Jones's activities be subject to an injunction." But that cannot be right, for there could be detectable but insignificant harm that is outweighed by the huge benefit of radio transmissions.' (135)

B19 comments,

But this will not do. As we have seen, there are indeed "detectable" effects, not "harms" due to waves emanating from bricks, water, the earth, the human body, etc. (135)

But this will not do. L14 is supposing, for the sake of argument, that there are "detectable but insignificant harms". It is absurd for B19 to counter that there are no such harms in fact.

\section{B19 continues:}

If we take Lester's claims to their logical conclusion [...] the courts will be inundated by all sorts of highly irregular claims. The proper reaction is to [...] dismiss them on the basis of being frivolous lawsuits. (135)
If the harms are known to be "insignificant", then there is no reason to expect them to go to court. But if some case were brought, then of course it would be dismissed. However, it would not be dismissed on the basis that there were no "harm" (strictly, proactive imposition: which, ex hypothesi, there is), but because it is obviously trivial compared to the serious proactive imposition of disallowing the behaviours that bring it about.

\section{"2.4 Probability of risk"}

B19 quotes L14's analysis of the libertarian response to plane-crash risks, and responds:

In my view, in contrast, no "weighing" is necessary. The issue is, is flying a plane a threat to those on the ground, not whether or not it is a risk. (135)

A threat that is extremely unlikely to occur is, ipso facto, still a threat. And clearly there is a very small threat. That threat can only be understood and quantified as a statistical risk. And it is proactively imposed on the people on the ground. (Obviously, "threat" here is being used to mean the mere possibility of an unwanted occurrence, not an attempt to bring about someone else's compliance.)

Everything is a risk, everything. There is some small risk that when a normal person walks, he will keel over and accidentally commit assault and battery on someone else on the sidewalk. (135)

An accident is incompatible with either of the crimes of assault or battery.

Given air safety records, they do not impose a threat. (135)

This is argument by denying the facts or redefining words. An extremely small threat is still a threat.

Yes, yes, if crashes per passenger mile quadrupled, and then quadrupled once again, God forbid, we would be approaching, if not surpassing, that gray area where the mere risk turns into the sort of threat proscribed by libertarianism. (135)

By what abstract theory of liberty, or practical libertarianism contingently shown to be implied by such a theory, does a risk or threat become proscribable? We are not told. And what of the proactive imposition on the people that are 
thereby disallowed that activity? By what principle do we determine whether any compensation is due? We are not told. Again, B19's ad hoc interpretation of a theory of mere propertarianism is being presented as "libertarianism" simpliciter. Of course, there is a tacit theory of liberty that informs B19's interpretations. But it requires philosophy to make it explicit.

On this basis, Lester asserts that the "nonaggression principle is not 'intact and unscathed'["] as I would have it. I readily acquiesce in the view that the NAP alone, while it is necessary, it is not sufficient for a well-functioning legal system. (136)

The problem is that the "non-aggression principle"-even combined with "homesteading"is a sort of obscure and confused theory of what perfect liberty involves. But it is not practical as a rule because so-called "aggressions" (where our activities proactively impose on other people and their property to some degree) are inevitable in practice. B19 implicitly holds that "aggressions" cease to be "aggressions" when they are sufficiently small. But this is arbitrary. And what if there are clashing proactive impositions between two parties that are not small?

We need courts, hopefully, private ones, to deal with these gray areas: how close, and in what context, does your fist have to be to my nose so that I am justified in taking violent defensive action, what is the proper statutory rape cut-off age, etc. (136)

Courts would likely exist to deal with some "gray areas". However, they would require a proper theory of liberty if they are to deal with such cases in a principled and more precise libertarian way. Ad hoc practical rulings within B19's purely physical propertarian system would be approximate at best.

The NAP remains "intact and unscathed" as a principle, the attempts by Friedman and Lester to undermine it notwithstanding; (136)

11 It is trivial because all that we are being proactively denied are the natural resources that
As has been shown (but not necessarily understood), the "NAP" is an incoherent theoretical mess.

but it never was the be all and end all of an entire legal system. Says Lester: "Block has no adequate theoretical solution here." Of course, I do: the NAP. But an adequate theoretical solution can only do so much. It does not exhaust all of the libertarian law. (136)

The "NAP", plus anything, cannot be the solution to the problem that the "NAP" inherently entails problems (as has been explained). However, a proper theory of liberty can be used to solve all of the problems as to what libertarianism entailsincluding in that subset that comprises the law.

B19 concludes the section thus:

Let us end this section by considering Lester's view on the justification of selfownership. (136)

L14 offers no such "view". Self-ownership can be explained and defended by applying the abstract theory of liberty. However, it remains a conjecture for which there cannot be a supporting "justification".

Then B19 quotes footnote 10 in L14:

"Strictly speaking, in all normal cases, allowing the use of other people's bodies without their permission would be an immense proactive imposition on them. But not being allowed to do this would be a relatively trivial imposition.[11] Hence selfownership is derived from applying liberty as minimizing proactive impositions. But we no more need to try to weigh the difference than we need to weigh an elephant against an ant to determine which is heavier." (136)

To add some more detail: we can use the abstract theory of liberty to contingently derive that people must have ultimate control over their bodies (the bodies that they more or less are) if liberty is to be maximised in practice (the libertarian policy); only then can we add that institutionalising this as the

make up that other body. And we have similar use of resources in our own bodies. 
property right of self-ownership is contingently likely to make this ultimate control over their bodies more secure, and thereby more libertarian in practice.

\section{B19 comments:}

Oh yes, we do indeed need to "weigh" these matters. The only heart surgeon in town is about to go off to his vacation. What does he do on his holiday? Frivolous things: lying on the beach, playing poker, getting drunk, etc. Nor do these activities replenish the batteries of the doctor; as a matter of fact, they reduce them. At the same moment, townsfolk becomes ill and needs heart surgery. This man is the salt of the earth, an inventor, a family man, someone who will greatly increase the GDP. Yes, we have an "elephant against an ant" here. But the elephant is the patient, and the doctor is the ant. According to Lester, the physician should be compelled to at least postpone his vacation if not cancel it entirely. Surely, at least according to the utilitarianism suffered by both Lester and Friedman, the police would be justified in doing exactly that. Yet, it seems difficult to reconcile this sort of forced labor, not to say (short term, or partial) slavery, with libertarianism. (136)

L14 explains how self-ownership and external property is contingently derivable from an abstract theory of interpersonal liberty. Such a theory is necessary if we are to explain how certain property rights fit liberty while others don't. B19 completely misses the point, as ever. The implied putative reductio is another irrelevant ramble. L14 does not imply that "the physician should be compelled to at least postpone his vacation if not cancel it entirely". And L14 is not applying "utilitarianism" at all but a theory of liberty. What is the theory of liberty in B19? There is none. L14 implies the same propertarian conclusions as B19 in the imagined scenario. The only difference is that L14 can explain the relationship to interpersonal liberty. But the only way to understand this, and even fault it if it is faulty, is to go back to the philosophical arguments and criticise them carefully and precisely.

\section{"2.5 Homesteading"}

B19 asserts that,
For some reason, known, perhaps, only to himself, Lester in effect maintains that I support Locke's view that the earth belongs to "mankind in common." He offers no evidence for this false belief of his. (136)

L14 makes no such assertion or implication. And B19 "offers no evidence for this false belief", such as providing a quotation. B11 asks "where oh where did Friedman get the pernicious idea that 'land starts out belonging equally to everyone'?". And L14 merely points out that "it is famously repeated many times (the expression 'in common' 29 times) in Locke's Second Treatise of Civil Government".

Lester also queries my reliance on Locke for homesteading, that is, "mixing one's labor" with the land as a legitimate way of establishing ownership of it. How can I both insist that "Locke is a relatively poor representative of libertarian homesteading theory" and yet cite him on "mixing one's labor" with the land as a means of homesteading, he asks. It is simple. Locke is perhaps the most famous philosopher associated with this idea, and, yet, he erred in thinking, inconsistently, that land should be the common heritage of all mankind, that is, owned equally. (136)

One tool of philosophy is separating ideas that are conflated. The point is that B11's only theory of actual "homesteading" (initial acquisition) appears simply to be Locke's "mixing one's labor" theory. And it is not any part of that "homesteading" theory in itself whether the land is unowned, or owned in common, or any of an indefinite number of alternative initial circumstances. Perhaps Locke's initial-acquisition principle is logically incompatible with his assumption of common ownership (for how is it possible that other owners-in-common have no say?). But that possible incompatibility appears to illustrate that Locke's initial-acquisition theory must be independent of his theory of initial circumstances. A screwdriver can still be theorised as a tool for dealing with screws even if one's assumed circumstances involve no screws. Moreover, as is even quoted in L14, the Second Treatise apparently ignores the commonownership assumption in favour of a more neutral account where it asserts: "when he takes something from the state that nature has provided 
and left it in, he mixes his labour with it, thus joining to it something that is his own; and in that way he makes it his property."

B19 then quotes L14's three questions and answers concerning this "homesteading" theory and provides comments after each; which comments will be dealt with in turn at appropriate points.

\section{"My Comment on Lester's Q\&A1."}

That "minimize interpersonal proactive impositions" business is highly problematic. Yes, I vastly prefer to "minimize interpersonal interferences, aggressions, invasions, initiated constraints." (136)

The abstract theory of interpersonal liberty defended in L14 and here may be summarised as "the absence of [the constraints that are] interpersonal proactive impositions [of costs]". When there are clashes of such impositions we can only "minimize" them as the most libertarian policy. B19 here appears both to accept this abstract libertarian policy and to assert that, but not explain how, it is "highly problematic". No relationship between "homesteading" and "a clear theory of liberty"-which L14 specifically asks for here-is given in B19.

private property rights are hardly "ad hoc additions." (136)

L14 does not mention "private property rights" at all in either its question or its answer-let alone assert, as B19 implies, that they are "ad hoc additions". L14 is asking for an explanation of "homesteading" that is "in terms of liberty itself and not ad hoc additions". The "ad hoc additions" are anything that are not "liberty itself". Of course, B19 is assuming that "homesteading" immediately and unproblematically creates "private property rights". But where does a theory of liberty fit in? That is what L14 is asking. L14 gives a philosophical answer. B19 does not and cannot, as it simply starts and finishes with property and property alone. L14's philosophical answer has several stages that can, again, briefly be distinguished (but not explained and defended in detail here). 1) There is an abstract (non-propertarian and nonnormative) theory of interpersonal liberty in itself: 'the absence of constraints that are interpersonal proactively imposed costs' ('no proactive impositions', for short). 2) This implies the libertarian practical policy: in the event of contingent practical clashes over resources, there can only be a maximisation of such liberty. 3) The abstract theory and the practical policy are then used to derive what this implies in a state of nature: ultimate control of one's body and of unused resources that one starts to use, with consensual interactions and exchanges thereafter (plus full restitution for infractions). 4) Only at a fourth stage is it a practical implication of the libertarian policy that this ultimate control of resources can better be protected by institutionalising it as property that is protectable by enforceable law. 5) Defending (rather than illogical attempts at 'supporting' or 'justifying') the conjectural desirability of such a positive libertarian system from any and all criticisms. B19 simply leaps to the fourth propertarian stage without any philosophical background to explain how this property relates to a theory of liberty. Moreover, B19 conflates the fourth stage with an illogical version of the fifth stage: such 'libertarian' property is supposed to be 'supported' by being somehow axiomatically just.

Rather, they, along with the NAP, are the very heart and soul of this philosophy. (136)

As we have seen, there is no "philosophy" in B19's account. There is only a confused dogmatic catechism of propertarianism, of the kind that B19 advocates, including the "NAP". The "NAP", as has been shown, is unclear as regards so-called "aggression" ("violation" would be only somewhat clearer) and incapable of universal application because its inherent absolutism ("non" being, ipso facto, absolutist) cannot deal with the clashes that it implies in practice. B19 asserts that this mere absolutist propertarianism is "libertarianism" without explaining any philosophical relationship to liberty. However, none of the philosophical texts that defend this version of "libertarianism" are much better than B19. More surprising still, very few of the texts that criticise it are much better either. But at least both kinds are usually trying to deal with philosophical problems by attempting philosophical solutions.

Without private property rights, both in persons and in physical possessions, the very NAP makes no sense whatsoever. (136) 
As has been shown, even with private property rights the "NAP" is at best confused and indeterminate.

For, what is a kick in the teeth apart from a violation of someone's property in their own body? (136)

Good question. In fact, a "kick in the teeth" can be understood in an indefinitely large number of ways depending on the problem that one is trying to solve. Most relevant here, however, is that it is a proactive imposition by one person on another (assuming, as B19 appears to do, no background that makes this proportional defence, retaliation, or a voluntary fight, etc.). As interpersonal liberty is the absence of interpersonal proactive impositions, a "kick in the teeth" thereby flouts the liberty of the attacked person. There is no need whatsoever to mention the institution of property. In a world without property it would still flout interpersonal liberty. B19 is so blinkered by crude and dogmatic propertarianism that it cannot see anything except in terms of property. But this might have been different if it had at least attempted to explain the relationship of liberty to property.

\section{"My Comment on Lester's Q\&A2."}

Lester is a native speaker of the English language. Yet, he does not seem to realize that "mixing labor" with something is the very same thing as is "using" that very thing, whatever it is. (137)

It is possible to be "using" something without "mixing labor" with it: one can be "using" the position of the sun to tell the time, but one is not "mixing labor" with the sun. Conversely, it is possible to engage in "mixing labour" with something without thereby "using" it: to walk across unwanted mud is to be "mixing labor" (the labour of one's walk) with the mud, as the footprints attest, but one is not thereby "using" the mud. The idea that the English language itself shows "using" and "mixing labor" to be logically interderivable is fatuous. Philosophical problems are rarely, if ever, solved by resorting to the meanings of words, perhaps as found in dictionaries (which, in any case, merely record usage and not essential meanings).

B19 correctly criticises the labour theory of value, and then continues,
The "labor theory of initial acquisition" ... asks under what conditions property may be owned justly and answers only when the owner has mixed his labor with the material in question, or used it. (137)

This is a theory of initial acquisition that is just (but what is the general theory of justice?). Apart from conflating labour-mingling and use, it tells us nothing about how liberty is relevant.

B19 accepts that the "challenge regarding the 'sacred grove,' or the 'beauty spot,' or the 'nature preserve' is an important one" and refers the reader to another publication on the subject. However, footnote 19 gives a

Hint: people can homestead land indirectly, via cows and sheep. They can also do so for nature preserves by first capturing worms and bugs and mice, elsewhere, and then setting them loose in the soon to be privately owned, but not touched by human hands or feet, nature preserve. (137)

Presumably, this claim to "homestead land indirectly" must mean to mix one's own labour "indirectly". It's my land because I caused animals, insects, etc., to enter it. This is both ad hoc and unclear. If these things count as mixing one's own labour "indirectly" with land, then there is no clear account or limit as to what that really means. One may as well say that one deliberately breathed out carbon dioxide over some land and thereby homesteaded it, because of all the flora that eventually but inevitably took in some molecules of that carbon dioxide. Or maybe one flew overhead sprinkling water far and wide. This is the same sort of unconvincing and arbitrary approach used to attempt to deal with the problems with clashes of absolute property rights.

\section{B19 presses on:}

There is yet another reason why all the territory within the periphery must be homesteaded, and that merely building a fence around the property will not suffice. Consider the state of Ohio. Its boundaries form roughly a roundish square, so to speak. Suppose I were the first one in that area, and I built a fence around the entire Buckeye state. According to Lester, I would own the entire property .... (137) 
In a world where land, its attributes, and locationwere not scarce, such a boundary (with the intention of possessing all the land within it, for whatever purpose) might be a sufficient claim to ultimate control by the theory of liberty (and that ultimate control might then be institutionalised as property). The next person could simply, ex hypothesi, take another patch of equally good land and do the same, or whatever else he wanted. Other things being equal, it would be more of a proactive imposition to interfere with someone's current use of that land for whatever project he has, than it would be to require that people take another area of land for themselves. However, we do not live in such a world. In reality, land, its attributes, and location are scarce resources. Consequently, it is possible to initiate possession of so much land (which one did not, after all, create) that one proactively imposes to a significant degree on other people. If Ohio and, say, all the other 'states' (their land) were similarly originally possessed by only fifty single people, then that would have been a huge proactive imposition on all the people who would otherwise have found uses for this natural resource of land. And the same analysis would apply even if all of these owners had actually mixed their labour, whether directly or indirectly. Therefore, there is some theoretical limit here; but it cannot be made physically precise because it will be affected by contingent circumstances (and libertarian courts might need to adjudicate any conflicting claims by applying the theory of liberty and the libertymaximisation policy). However, this does not entail that there is some definite upper limit to one person's land possession; nor does it entail that possession always remains equally open to such libertarian challenge. As economic development proceeds, land in itself (rather than what has been built on it, or its location, etc.) becomes relatively less valuable and consensual transfer almost always becomes the least proactively imposing (i.e., liberty-maximising) option. Obviously, all this is far more theoretically complex and abstract than simple labour-mixing and absolute property rights. But, as we have seen, those two simplistic assumptions imply irresolvable problems and they are bereft of any philosophical link to liberty.

which, in and of itself, is highly problematic, since I have not even come close to mixing my labor even with every 10 square miles of its land. (137)

Presumably, with "indirect" labour-mixing (B19's insects, or a fine spray of insecticide, or even mere water; dropped from a plane, or whatever) it might be relatively easy to "homestead" vast areas.

Even worse, however, is, who is to say what is "inside" and what is "outside" of this periphery? Whenever a (squarish) circle is imposed upon a sphere such as earth, it is entirely arbitrary to claim that the smaller area is "inside" and that the bigger one is "outside." $(137-8)$

It can only be up to the boundary-builder to say what he intends by his boundary. But what he intends might be incompatible with liberty.

The point is, Lester's recipe could end up not merely with me owning all of Ohio, a manifest absurdity, in and of itself, but the entire remainder of the planet, apart from this one state, which is even more bizarre. (138)

As we have seen, there is no such implication. B19 is even more confused about the theory of liberty and how it applies than about labour-mixing and absolute property rights.

\section{"My Comment on Lester's Q\&A3."}

What if one person figures out how to make a rocket that will reach Mars, and, also, invents the technology to allow humans to live on the fourth planet. Everyone knows that for some reason, the earth will soon explode, and all those still remaining here will perish. Do others then have to pay whatever he chooses to charge or go without being able to live on Mars?

Yes, of course, they do. That is the way the cookie crumbles. This sounds harsh, but, private property rights, and the NAP, über alles. (138)

And the same result follows from applying the theory of liberty. There is no proactively imposed interpersonal cost here.

Now let me pose a counter question to Lester, and, also, answer it for him. Under which conditions are people more likely to make these inventions, and amass the capital that will allow us to transfer to Mars and 
successfully live there? Is it one which respects private property rights, and the NAP, as all good Rothbardians do, or is this more likely to occur under Lesternomics, (138)

There is simply no clash in this example between B19's interpretation of "private property rights, and the NAP" and correctly interpreted "Lesternomics". The abstract theory of liberty, when applied, entails private property that fits liberty; which it does in the example. This is not in any way an economics theory, as the portmanteau "Lesternomics" appears to suggest. It is an abstract eleutherological-conjecturalist philosophical theory of libertarianism (however, if one must eponymise it, 'Lesterism' is both shorter and necessarily correct).

where private property rights can be abrogated, and the NAP violated, as long as someone, thinks that by doing so, this will "minimize interpersonal proactive impositions?" (138)

It is not a matter of what "someone, thinks". It is a matter of what factually minimises interpersonal proactive impositions. Apart from exceptional cases, strict private property will do this. B19 does not present here even a prima facie clash between absolute private property and what the theory of liberty entails.

To ask this is to answer it. Of course, economic freedom is not only the only just system, but it is also the most prosperous one. It is also the one most likely to get us to Mars, when we need to do so. (138)

Presumably, "economic freedom" is the ability to use your property as you wish. How that ability and property relates to liberty is not explained in B19. If property is derivable from applying the theory of liberty-and is both just and economically efficient-it might be "the only just system" and "the most prosperous one"-also "most likely to get us to Mars, when we need to do so" (the latter two points being consequentialist). However, that it is "just" and also "most prosperous" are entirely separate conjectures and not part of the theories of what liberty is in the abstract or how it applies to the world in terms of property.

The identical considerations apply to water. We are much more likely to have welldeveloped water resources under private ownership and the NAP (Block and Nelson, 2015), than with any other possible system. It sounds horrendous, and preposterous, that the water "monopolist" could charge an arm and a leg for this product; but, paradoxically, if we allow for this possibility in law, it is less likely to occur than if not. (138)

This utilitarian (or consequentialist, at least) longrun defence by B19 is approximately correct as regards the long-run (except that the NAP does not make proper sense in itself and entails clashes of absolute property rights). But it does not adequately deal with the specific problem posed in L14: "What if someone 'homesteads' the sole natural water supply: in a drought, do others then have to pay whatever he chooses to charge or go without water?" (116). L14 goes on to explain that the owner

is, ex hypothesi, not the producer or the creator or-we may suppose-even the preserver of the water itself (no matter how much labour-mingling was involved). He is merely in the way of others who need that natural water supply. Therefore, the libertarian principle of minimizing interpersonal proactive impositions (or constraints, etc.) overrides his ownership. (L14, 116)

B19 asks,

What are the alternatives? There are only two. One, non-ownership of water, in which case it will disappear, due to the tragedy of the commons. Two, the government bureaucrat/politician will own all the water and will do to the populace precisely what Lester fears will emanate from the private owner if any of it is left after their depredations. (138)

There is a third more-libertarian option. There are relatively rare cases where an owner proactively imposes by his ownership of a natural resource, such as has been supposed here. Another example would be if a landowner wouldn't allow someone to escape from some life-threatening disaster by a brief trespass across his land as the only escape route. In such cases, liberty entails that absolute property rights be modified just enough to stop the greater proactive imposition. This maximisation of liberty need not in any way 
undermine general private-property rights or require any state involvement. In new or unusual cases matters might have to be taken to a libertarian court to work out the most libertarian solution. In regularly occurring cases, such as needing to escape across someone's land, what is allowed and required would probably become common knowledge. Exactly what is required will always depend on the contingent details of the problem. What about our owner of the sole natural water supply in a drought? Assume, ad arguendo, an inexhaustible aquifer entirely under the middle of his land with no practical way of slant-drilling, etc., before there are many deaths by thirst. Then the owner might be required by a libertarian court to somehow allow access to that water until the drought ended (but compensation for any inconvenience, costs, or damage to him will be due). This is because, ex hypothesi, people would have had access to that water if he were simply never there. Strict private property usually maximises liberty but there are exceptions.

Libertarianism, properly [understood], does not countenance anyone['s] "overrid(ing) ([anyone] else's) ownership." (138)

B19's theory of "libertarianism" is only one among competing theories. And it is one without any theory of liberty to explain anything at all. Whether the liberty that libertarianism assumes, whether explicitly or implicitly, ever allows any overriding of ownership is a philosophical question. That question cannot properly be answered by dogmatically asserting that "libertarianism, properly [understood]" entails absolute property rights.

We have a word for such "overriding." It is called theft. This is anathema to liberty, its polar opposite. (138)

One type of interference with liberty is theft. Many other interferences are not theft (assault, land trespass, criminal damage, etc.). To be incompatible is not necessarily to be a "polar opposite". The "polar opposite" of theft is possibly charity. The "polar opposite" of liberty is something more like totalitarianism.

Contrary to Lester, "homesteading is (indeed) inherently libertarian." I often think of libertarianism as a two-sided coin. On one side is the NAP. The other side? Wait for it: private property rights that are not "overridden." To say that libertarianism "is ultimately pre-propertarian" is to seriously misunderstand and deprecate this viewpoint.

The "NAP" is only a way of saying "private property rights that are not "overridden"'. "The other side" of the coin has to be "homesteading" itself (how property is initially acquired). As has been shown, this essay has a better understanding of B19's "viewpoint" than B19 does itself. At the same time, B19 has utterly failed to grasp or adequately reply to any of the philosophical arguments in L14.

\section{"2.6 Resource value"}

I have no comment on this short section of the Lester paper. I mention it only because I want to follow the organization of his essay. (139)

In fact, L14 follows the organisation of B11. Hence the quotation marks in L14.

\section{"2.7 Crime and punishment"}

B19 objects to L14's assertion that "to duly convict and punish an innocent man who one honestly believes is almost certainly guilty would be possibly tortious but not criminal." It responds, "Motive schmotive" if someone "is a kidnapper in effect, if not in intention, and kidnapping is a crime, [then he] is a criminal" (139). B19 advocates that if the "policeman, judge, or jailer" is found to have "erred, they would pay for their mistake not only in terms of lost revenue but with actual criminal charges". Perhaps that would include any jury members that "erred" as well. It is hard to see how such a system could function. However, much common-law-based criminal law usually requires both an actus reus (a guilty act) and a mens rea (a guilty mind). If we don't make this intuitive and useful distinction, then that appears to imply that all unintended wrongs are always also crimes. Hence, libertarian legal systems would be highly unlikely to abandon it completely.

\section{"2.8 Extent of punishment"}

B19 rehearses how, according to Rothbardism, "proper libertarian punishment consists of four levels" (140). It does not explain how these relate to a theory of liberty. Then it asserts, 
Lester objects to the second of these payments on the ground that they are "somewhat arbitrary." (140)

No, L14 objects that all of "Block's reply provides no clear theoretical connection to liberty and is somewhat arbitrary as a consequence". Quite a different criticism. There is no objection, in fact, in L14 to the view that "the punishment should fit the crime". Relating what is done to liberty is the sole issue.

B19 quotes L14 and then says,

We want both full compensation and retribution from the criminal. $X$ 's return to $Y$ of the automobile he stole from him shouldn't "count." That is hardly a punishment to $X$. (140)

Libertarianism requires full rectification to undo any infractions of liberty. If you have full rectification for a criminal infraction of liberty, then liberty has-ipso facto-been fully restored. You are, ex hypothesi, not worse off than before. Nothing further needs to be done. You are, however, at liberty to take all—or any part-of your rectification as retribution: reactively imposing up to equivalent damage. But to go beyond full rectification, however you take it, would itself be to proactively impose on the original imposer. B19 advocates both full rectification and then to have it all again as an additional "punishment". This is an arbitrary proactive imposition that has no basis in a theory of liberty. It is the infliction of an equivalent amount of a proactive imposition but on the original imposer. What appears to be at play here (as B19 next goes on to make plain) is a background assumption that without such additional punishment there would be insufficient deterrence of criminal activity. But in the specific example in question there is no attempt to evade rectification and therefore the risk-multiplier ${ }^{12}$ (proportional to the statistical chance of evasion) does not come into play. Biblical lex talionis might usually be some approximation to the correct libertarian rectification for crime only because there is usually the attempt to evade detection. However, that will probably fall far short of most risk-multiplier calculations.
B19 then asserts that L14 "looks askance at forcing the criminal to pay for the costs of searching for and capturing him" (141). No, L14 merely explains how "if too much is spent (perhaps by some obsessively vengeful billionaire), then it would itself go beyond libertarian rectification if it were all passed on to the criminal". B19 says, "this amounts to coddling the criminal". But this is an irony given that libertarian risk-multiplier rectification will usually exceed anything in B19's arbitrary theory.

\section{"2.9 The madman"}

B19 quotes L14's explanation of a clash-i.e., incompatibility-of (liberty-derived property) rights. To make it clear, the clash is that-in the supposed scenario-we cannot have both, 1) observance of the right of the crowd not to suffer some murders, and 2) observance of the right of the gun-owner to repossess (not merely to keep in the first place) his weapon from the person taking it to shoot the prospective murderer. Logically, the observance of one or other right must now be breached: either some murders must occur or the owner of the gun must unwillingly go without his gun for a while. There is no clash between the right of the owner to hold on to his gun throughout and the right of the crowd not suffer some murders. Thus, there is no direct-or inherent-clash between the libertarian rights in question. But an indirect clash becomes unavoidable once the gun is seized. B19 holds that that there is not even an indirect clash and that it would be a problem for libertarianism if there were. Both of these propositions appear to be false. The relevant part is where B19 says,

Is there a clash of rights between the rifle owner and those who would seize it from him in order to protect the crowd? No. The owner of the rifle has the right to it, and anyone who wants to take it from him for this or any other purpose is in the wrong. No clash here. (142)

There is, indeed, no clash there. But that is not the clashing situation. We need to suppose that the rifle has already been seized against consent in order to stops the murders. Then we have two possibilities: either the gun-seizing "hero" protects

12 See Lester, 2000. 
the rights of the crowd, or the gun is immediately returned to its rightful owner. Once at that stage, it is impossible for both rights to be observed. But this does not seem to be a serious theoretical problem for libertarianism. As L14 observes, matters can be rectified-even assuming deontological libertarianism-by the gun-seizer later paying full restitution to the owner (which members of the crowd may well wish to pay on his behalf).

\section{B19 continues,}

If I have a right to something, you have an obligation to support me. (142)

This appears to be a slip. On a natural interpretation it does not appear libertarian. We usually only require non-interference, not positive "support".

B19 then correctly lists several "negative rights", but concludes

the so-called right to "self-preservation" is a positive right. For, if I indeed do have a right to self-preservation, you have an obligation to preserve my life. (142)

It does not follow from the assumption of a selfpreservation right that anyone has an obligation to help with someone's self-preservation. It does not clash with that right to let people perish. And if someone breaches libertarian property in order to preserve his own life, then he still owes full libertarian compensation for that breach.

B19 then cites three examples given in L14,

First, the hiker who breaks into a cabin to save his own life.

Second, the falling man who manages to grasp onto a flagpole.

Third, the person who places landmines in his garden "to deal with the trespassing of local children who use it as a shortcut." (142)

B19 asserts that the "hiker is a criminal trespasser" (143). Trespass to land, on its own, is not usually regarded as a crime: people are not given criminal

13 "This case can also be obviated by the building manager imposing contractual rules on all tenants or condo owners to keep a gun handy, and allow flagpole holders access to their premises." (143) If records merely for wandering on to someone else's land without permission. It seems doubtful that libertarian courts would change this. However, breaking and entering is a crime. B19 then proceeds to say nothing that contradicts anything actually stated or implied in L14, and concludes with a more extreme position than that taken in L14, "invade the premises of the cabin owner, by all means. But, also, admit you are a criminal, and pay what is owed by you" (143). To put it mildly, there is no libertarian obligation to encourage people to "invade ... by all means".

B19 then rehearses the flagpole-faller case and tells us that

as he is moving hand over hand to safety toward the deck, the owner of that apartment demands that he drop to his death, otherwise she will shoot him for trespassing ... the woman was raped last week by someone who looks just like him, and fears for her safety. (143)

According to B19's footnote 27, at least, she shoots him (but, apparently, unnecessarily ${ }^{13}$ ). Even if he is the very same rapist, why can't she shut and lock her deck door and hold him at bay through the glass with the gun while she phones for the police (but shoot him if he tries to break in), or simply run away? We are not told. The scenario is somewhat under-specified. Inflicting an unnecessary death for trespassing is itself to proactively impose hugely on the trespasser. It is absurd for B19 to ask and answer,

Has she no rights in the matter as the owner of the property now under dispute? Not according to those who use this example as a means of undermining private property rights. (143)

She has both the rights and the means to protect herself without resorting to what even a fully libertarian court might regard as manslaughter, at least. It is possible, of course, to come up with a more highly-specified example that makes B19's case more solid: maybe she cannot lock the door

that is sufficient to make it be "obviated" then, it seems, the shooting in the assumed case is not needed for her defence. 
or run away, and he says he intends to kill her. But then her shooting of him would seem entirely libertarian by the theory of liberty as well.

B19 asserts of the third example, a picture of a fully "private enterprise" society would not give rise to such a problem. But if we "assume none of this", then "one child killed in this way, not murdered, would soon ensure the obviation of this practice. Large-scale capitalists are not that stupid." B19 appears to be, again, appealing to long-run consequentialism without any theory of liberty. However, with a theory of liberty (as the absence of proactive impositions) and libertarian policy (minimise any unavoidable clashes, allow proportionate defence, and otherwise enforce full rectification) it looks as though killing for minor trespass is so entirely disproportionate that it becomes itself a proactive imposition, or "aggression". Consequently, this "difficulty is created by the fact" that B19 has only an absolutist theory of property-rights that is interpreted in a fanatical way that flouts human liberty.

\section{"2.10 Contradiction in rights"}

B19 concedes L14's view that a "hierarchy of rights is perfectly conceivable". B19 cites politically correct 'rights' as one example. It is also agreed that the "right not to be murdered is stronger, higher up in the hierarchy than the right not to be raped", etc. (but why if all rights are equally absolute?). That is, implicitly, that there is an intrapersonal hierarchy. B19 then incorrectly supposes that what L14 "means" is that "the hero's right to save the members of the crowd can trump the right of the innocent gun owner to keep his property to himself" (144). There is no such assertion or implication in L14. The point is purely logical, "difficult for [B19] to process this as it may be".

\section{"2.11 The draft"}

B19 does not contradict anything in L14 here. Instead, it changes the example to assert that a pacifist who is parent,

occupies the guardianship role, since he claims to be a parent, but, also, explicitly does not do so, since he is a pacifist. Pacifists thus cannot be proper parents. When they claim this honorific, they are rights violators, hence, criminals. (145)
Presumably, a pacifist could protect his children by taking them to a country not at war. Even in the two so-called 'World Wars' there were plenty of such countries. Or if the issue is that there is some attacker of his children, then a parent could physically intervene in a variety of ways, which might include physical constraints, that do not thereby amount to a violent attack on the attacker. Is an implication of B19's view that pacifist parents (as "rights violators, hence, criminals") should be prosecuted and their children taken from them? We are not told.

\section{“3 FURTHER CRITICISMS"}

\section{"3.1 Critique of utilitarian libertarianism"}

Here, [L14] objects to my characterizing utilitarianism as an exercise in "nose counting." Do not ask me what this has to do with Puritans objecting to sexual intercourse on the ground it might lead to dancing.

Crucial to the, here misunderstood and mangled, joke is "love-making while standing". The relevance is this. Even if it were true, it cannot be a devastating objection to utilitarianism (or to standing sexual intercourse) simply that it leads to counting individuals (or to dancing). In one similar sense libertarianism itself clearly counts individuals: the fewer the better of individuals having crime $X$ inflicted on them. But there is also this crucial additional error: "it seeks the greatest good for the greatest number, does it not?" (145) No, it doesn't. Admittedly, "the greatest happiness of the greatest number" is the famous formulation of the principle Jeremy Bentham adopted in his $A$ Fragment on Government (1776). However, this is a rough-and-ready expression that cannot accurately capture utilitarianism. For, logically, utilitarianism must seek the "greatest good" in terms of some version of "utility" irrespective of any actual numbers of people involved. Therefore, far from being a knock-down point, "nosecounting" is a weak, vague, and inaccurate criticism.

\section{"3.2 Weaknesses in utility theory"}

B19 now conflates several different sections and ignores most of the arguments. However, it appears to accept the hedonometer for the sake of argument and says, 
this here pen rates at 8 utils on the hedonometer; while this sandwich over there clocks in at 16 utils. That would mean that the person who scores these values on the hedonometer would regard two pens and one sandwich equally. (146)

Possibly not, because of diminishing marginal utility.

The challenge is not an empirical one, and no "testable science (will) eventually" solve this problem.

Ex hypothesi, hedonometer readings could be taken. B19 proceeds to show that it either does not really grant the assumption, after all, or does not understand it.

L14 then changes to the topic of "rough-andready interpersonal comparisons of utility". But B19 mistakenly assumes that this is still "talking about a hedonometer" (147). Then B19 insists that "indifference is impossible, meaningless" in "technical economics" (but no technical explanation is offered). There is no reference to indifference anywhere in L14. And L14 does not assert that it is impossible for something to be meaningless.

B19 notes L14's assertion that utilitarianlibertarianism does not entail that "all people have equal utilities" but restates that it does and that otherwise it is "is vulnerable to the 'utility monster' objection". B19 does not answer L14's various arguments on both these issues beyond asserting that it amounts to "twists and turns" which "changes the subject" (147). Unfortunately for $\mathrm{B} 19$, precise arguments require precise replies. The position taken in L14, and elsewhere, is that utilitarianism (or preference utilitarianism, at least) is often too easily and quickly dismissed. If we allow for the sake of argument that we can make approximate sense of it, then it appears to imply libertarian rules as the most utilitarian rules. This is both very interesting and very important as regards defending libertarianism from welfaretype criticisms (such defences do not imply advocating "utilitarianism"). And B19 itself makes claims compatible with this when it argues that we would all be better off in the long run with libertarianism ("Yes, 'liberty generally promotes human welfare"' (131); "Of course, economic freedom ... is also the most prosperous one. It is also the one most likely to get us to Mars, when we need to do so" (138); "We are much more likely to have well-developed water resources under private ownership and the NAP" (138); "one child killed in this way, not murdered, would soon ensure the obviation of this practice. Large-scale capitalists are not that stupid." (144)). If libertarianism really were a disaster for human welfare, then why would anyone want to have it? In fact, we see that it promotes human welfare by "rough-and-ready interpersonal comparisons of utility" (plus additional theories and arguments mainly from economics and philosophy, but also other social sciences).

\section{B19's careless replies continue:}

Lester notes that I question Friedman's freemarket anarchist credentials. (148)

On the contrary, L14 says "Block notes Friedman's free market anarchist credentials. But he objects that 'Friedman bases his viewpoint on these matters on utilitarian, not deontological or principled libertarian grounds"'.

B19 notes L14's assertion that "someone is a libertarian if he advocates universal interpersonal liberty. ... One's motives for advocating universal liberty are a separate matter." B19 replies,

Suppose someone supports libertarian conclusions (end the Fed; no minimum wage law; legalize drugs, pornography, gambling prostitution; bring all U.S troops home), but does so because he is a misanthrope, and thinks these policies will promote human misery. (148)

Yes, he is a libertarian but for misanthropic reasons-unlikely as this logical possibility is. Does this clash with the earlier assertion from L14 (see 2.1 above) that the libertarian ideology involves factual and moral theses? Not if that is taken as referring to how libertarianism is typically advocated (and even misanthropic reasons might be due, for instance, to fanatical environmentalist morals). But non-moral advocacy is logically conceivable (perhaps a non-moral person might advocate libertarianism purely as an instrumental modus vivendi).

Or, posit that a person adopts libertarianism because he is confused, and thinks this philosophy opposes private property rights, 
the NAP, limited government and economic freedom. (148)

Such a person does not adopt any form of libertarianism. He is simply confused about the meaning of the word. Therefore, these two examples do not show that "motives are not entirely irrelevant to this categorization" (148).

B19 then divides "the libertarian world into five sections, in order of their purity" and places David Friedman

Right there at the very top. [...] I was only questioning, querying, his bona fides, not rejecting them. (148)

This essay would place Block's writings near the top of its own classifications (were it to make them, which it won't). Their 'absolutist propertarianism' (but with confused exceptions for very minor invasions) is almost, but not entirely, at the level of a system based on an abstract theory of liberty and what that entails in practice.

\section{"4 CONCLUSION"}

B19 defends the criticism of "Freidman's (sic) scholarship" and asserts that L14 "criticizes [B11] for being too harsh, and a bit hypocritical" (no such latter word, or variation thereof, appears in L14). B19 insists,

there is all the world of difference between the hearsay style of Friedman, and my not citing all well-known aspects of the "philosophical literature." (148)

There was no request in L14 for "all well-known aspects". But both L14 (which B19 is criticising) and this essay are primarily philosophical.

Lester fails to point out any instances of my specific dereliction in this regard (148)

Here are two specific refutations, although one would suffice:

"where oh where did Friedman get the pernicious idea that "land starts out belonging equally to everyone'?" ... it is famously repeated many times ... in Locke's Second Treatise of Civil Government (L14, 115)

I first ought to mention, as Block does not, that the "utility monster" was, as far as I know, originally posited as a problem for utilitarianism by Robert Nozick [1974, 41]. (L14, 129)

It is not that it matters; what matters are the arguments themselves. Rather, it is to point out the somewhat self-undermining nature of the harsh criticism of Friedman.

B19 kindly closes with a compliment (and, to be fair, it was not the only one),

my compliment to Friedman ... applies to Lester as well. When you are in an intellectual battle with the latter, you are also in a serious battle. Moreover, I repeat that on several occasions Lester's criticisms of my critique of Friedman were right on the money, and I again thank him for them.

At risk of appearing ungrateful, here is a brief response. Debate is better viewed as intellectual cooperation. As critical rationalism explains, all we have are unsupported assumptions (however thorough the explanatory-not supportingarguments and replies to criticisms) and so we need to continue to seek the best criticisms that we can find. But when the issues are fundamentally philosophical, then those criticisms need to engage with the arguments at a philosophical level. Repetition of propertarian dogmata cannot do this. And most of B19 appears to take that approach. It is not possible to win at chess using the rules of checkers. That said, B19 does at least attempt to take on the libertarian theory defended here.

\section{CODA}

Libertarianism is important; it would be hard to exaggerate how important. It matters whether it is philosophically confused. The four main general types of libertarianism are deontological (about rights and duties), consequentialist (about overall outcomes), contractarian (about a social contract), and eleutherological (about an abstract theory of liberty). None of those types inherently entail any epistemology, despite contingent conflations in most expositions. Therefore, it is a logically separate matter that there are two main general types of epistemology: justificationist (about supporting foundations) and critical rationalist (about conjecture and criticism). In terms of what is advocated in practice, there may be relatively little to distinguish eleutherological-conjecturalist 
libertarianism and the other varieties. But in philosophical terms there is a world of difference. It has to be repeated until it is taken seriously: libertarianism without an abstract theory of liberty is on a par with utilitarianism without an abstract theory of utility; libertarianism with a justificationist approach is illogical dogma. Whether explicitly or implicitly, many critical texts have sound arguments refuting variations on these two types of error. They then invalidly assume that libertarianism as such is thereby philosophically refuted.

\section{WORKS CITED}

Block, W. E. (2011). "David Friedman and Libertarianism: A Critique", Libertarian Papers, 3: 35, 1-33.

Block, W. E. (2019). "Response to J. C. Lester on David Friedman on Libertarian Theory", MEST Journal, $7: 1,127-155$.

Lester, J. C. (2000). "Libertarian Rectification: Restitution, Retribution, and the Risk-Multiplier", Journal of Value Inquiry, 34 (2/3), 287-297.

Lester, J. C. (2014). "A Critical Commentary on Block 2011: 'David Friedman and Libertarianism: a Critique' and a Comparison with Lester [2000] 2012's Responses to Friedman", Explaining Libertarianism: Some Philosophical Arguments, Buckingham: The University of Buckingham Press, chap. 8.

Lester, J. C. (2019). "The Heterodox 'Fourth Paradigm' of Libertarianism: an Abstract Eleutherology plus Critical Rationalism", Journal of Libertarian Studies, Vol. 23: 91-116.

Lester, J. C. (2020a). "How Abstract Liberty Relates to Private Property: a One-Page Outline", PhilPapers, https://philpapers.org/rec/LESTAL.

Lester, J. C. (2020b). "Eleutherological-Conjecturalist Libertarianism: a One-Page Guide", PhilPapers, https://philpapers.org/rec/INDNLA.

Miller, D. W. (1994). Critical Rationalism: A Restatement and Defence, Chicago and La Salle, III.: Open Court.

Nozick, R. (1974). Anarchy, State, and Utopia, Oxford: Basil Blackwell.

Popper, K. R. ([1963] 1978). Conjectures and Refutations, London: Routledge \& Kegan Paul.

Received for publication: $\quad 05.09 .2020$

Revision received: $\quad 22.09 .2020$

Accepted for publication: $\quad 30.12 .2020$

\section{How to cite this article?}

Style - APA Sixth Edition:

Lester, J. C. (2021, January 15). Libertarian philosophy versus propertarian dogma: A further reply to Block. (Z. Cekerevac, Ed.) MEST Journal, 9(1), 106-127. doi:10.12709/mest.09.09.01.14

Style - Chicago Sixteenth Edition:

Lester, J. C. 2021. "Libertarian philosophy versus propertarian dogma: A further reply to Block." Edited by Zoran Cekerevac. MEST Journal (MESTE) 9 (1): 106-127. doi:10.12709/mest.09.09.01.14.

Style - GOST Name Sort:

Lester J. C. Libertarian philosophy versus propertarian dogma: A further reply to Block [Journal] // MEST Journal / ed. Cekerevac Zoran. - Belgrade - Toronto : MESTE, January 15, 2021. - 1 : Vol. 9. pp. 106-127. 
Style - Harvard Anglia:

Lester, J. C., 2021. Libertarian philosophy versus propertarian dogma: A further reply to Block. MEST Journal, 15 January, 9(1), pp. 106-127.

Style - ISO 690 Numerical Reference:

Libertarian philosophy versus propertarian dogma: A further reply to Block. Lester, J. C. [ed.] Zoran

Cekerevac. 1, Belgrade - Toronto : MESTE, January 15, 2021, MEST Journal, Vol. 9, pp. 106-127 